\title{
Wayang Kulit Cirebon: Warisan Diplomasi Seni Budaya Nusantara
}

\author{
Moh. Isa Pramana Koesoemadinata \\ Fakultas Seni Rupa dan Desain, Institut Teknologi Bandung, \\ Jalan Ganesa No. 10, Bandung 40132, Indonesia \\ Email: dronacarya@yahoo.co.id
}

\begin{abstract}
Abstrak. Seni pertunjukan Wayang Kulit merupakan seni tradisional yang sejak lama berkembang di kawasan Asia Tenggara. Di Indonesia, Malaysia dan Thailand, selain kisah-kisah lokal, wayang kulit banyak menyajikan kisah-kisah India Ramayana dan Mahabharata sebagai media pengajaran agama HinduBuddha. Saat agama Islam menyebar di kawasan ini, wayang kulit Jawa dan Melayu tetap berkembang bahkan dipergunakan sebagai media dakwah. Dalam perkembangannya di masa Islam, wayang kulit Jawa melibatkan peranan dan pengaruh para ulama Sufi dan para penguasa lokal. Pembentukan, penggubahan dan penciptaan visual boneka wayang kulit berikut kesusastraan dan karawitannya digagas langsung oleh Wali Sanga dan raja-raja Jawa berikutnya. Tulisan ini mengangkat wayang kulit Cirebon yang berusia kuno dan membahas kekhasan tiap atribut visualnya yang merupakan refleksi jejak-jejak akulturasi berbagai budaya (Jawa, Cina) dan kepercayaan (animisme, Hindu-Buddha, Islam). Wayang kulit Cirebon merupakan bukti pada masa awal berkembangnya agama Islam di Jawa, telah terjadi diplomasi antarbudaya dan kepercayaan secara damai melalui media kesenian sebagai jembatannya. Seni tradisional tersebut merupakan warisan bagi generasi muda sekarang dan mendatang, bukan segi estetikanya belaka, namun sebagai suatu filosofi dan strategi diplomasi lintas budaya dan kepercayaan yang wajib disadari, dipahami dan diamalkan pragmatikanya. Sesuai asal katanya, "wayang", ia merefleksikan keberhasilan diplomasi di masa lalu yang potensial diaplikasikan pada masa kini, demi lahirnya hubungan harmonis antara keanekaragaman budaya di tengah-tengah pesatnya deru globalisasi.
\end{abstract}

Kata Kunci: diplomasi budaya; media; refleksi; wayang kulit Cirebon.

Abstract. The wayang kulit (shadow puppet) theatre is a traditional art form that has thrived in Southeast Asia for a long time. In Indonesia, Malaysia and Thailand, apart from local stories, wayang kulit presents Indian epics, such as the Ramayana and Mahabharata, as a medium for Hindu-Buddhist teachings. When Islam spread in this region, the Javanese and Malay wayang kulit still kept developing, even when it was being repurposed for Islamic preaching. In its development in the Islamic era, the Javanese wayang kulit incorporated the role and influence of Sufi scholars and local rulers. The visual form, composition, and creation of the wayang kulit puppets along with the prose and musical arrangements were directly inspired by the Wali Sanga (Nine Apostles) and the

Received October $29^{\text {th }}, 2009$, Revised October $29^{\text {th }}, 2013$, Accepted for publication November $8^{\text {th }}, 2013$. Copyright @ 2013 Published by LPPM ITB, ISSN: 1978-3078, DOI: 10.5614/itbj.vad.2013.4.2.6 
following Javanese kings themselves. This paper presents the historic wayang kulit of Cirebon and discusses its unique visual features, which reflect acculturation between ethnicities (Javanese, Chinese) as well as beliefs (local animism, Hindu-Buddhism, Islam). The historic wayang kulit of Cirebon proved that a peaceful, cross-cultural and religious diplomacy took place through the medium of art since the early stages of deployment of Islam in Java. This traditional art is a legacy for current and future younger generations, not only because of the aesthetical aspect, but also as a cross-cultural diplomacy strategy and philosophy that must be acknowledged, understood, and practiced. In accordance with the meaning of the word, 'wayang' (reflection) reflects a successful diplomacy of the past that can potentially be applied in the present, hoping harmonic relationships can emerge from cultural diversity in the midst of rapid globalization.

Keywords: cultural diplomacy; media; reflection; wayang kulit of Cirebon.

\section{Pendahuluan}

Ditinjau dari bahannya, boneka wayang banyak ragamnya. Ada wayang golek yang terbuat dari kayu, wayang beber yang digambar di atas kain, ada wayang yang dibuat dari anyaman rumput, bahkan banyak wayang mainan yang dibuat dari kardus, plastik, ada yang berbentuk dua dimensi ataupun tiga dimensi dan sebagainya. Namun jenis wayang yang akan dibicarakan di sini adalah yang dibuat dari bahan kulit. Pengertian "wayang kulit" di sini adalah boneka pipih dua dimensi, yang dibuat dari kulit kerbau atau sapi.

Aspek wayang yang akan dibicarakan ini lebih menukik pada aspek visual. Selama ini masalah visual wayang masih jarang dijadikan sebagai kajian ilmiah akademis daripada aspek filsafat, sastra, karawitan, dan teater yang sudah banyak diteliti oleh berbagai ahli dari dalam dan luar negeri. Selain itu wayang kulit yang lebih banyak dibahas di sini adalah wayang kulit di Pulau Jawa, tepatnya gaya Cirebonan, yang saat ini sedang menjadi fokus penelitian penulis. Adapun alasan pemilihannya akan dibahas dalam bagian berikutnya. Hipotesis penulis di sini yaitu wayang kulit Cirebon memiliki visual yang unik, kuna dan memuat berbagai pengaruh budaya dan kepercayaan sehingga pantas dianggap sebagai media diplomasi budaya.

\section{$2 \quad$ Metodologi}

Yang akan dilakukan dalam penelitian ini adalah memaparkan detail dari aspek visual beberapa artefak wayang kulit Cirebon terpilih, kemudian memperbandingkannya dengan wayang Jawa lainnya juga pada imaji-imaji serupa, yaitu relief candi dan ilustrasi dari naskah lontar kuna. Berdasarkan hasil perbandingan tersebut, dibuat suatu kesimpulan atau hipotesis. 
Penelitian dilakukan di daerah Cirebon dan sekitarnya, yaitu kotamadya Cirebon di Keraton Kacirebonan dan sejumlah kediaman kolektor, lalu di beberapa kecamatan dan kelurahan sekitarnya seperti Arjawinangun, Mertasinga, Cimara, Balad dan sebagainya.

Metodologi yang dipakai adalah Metode Kualitatif atau Metode Artistik. Metode ini sesuai untuk penelitian yang berhubungan dengan teks seni dan budaya, juga dilakukan interpretasi pada data-data yang telah dikumpulkan. Berbagai metode yang dilakukan di sini adalah metode pengumpulan data, metode pengolahan data, dan metode analisis data yang bersifat deskriptif.

\section{$3 \quad$ Wayang Kulit di Asia Tenggara}

Seni pertunjukan wayang kulit adalah bukan hal yang baru lagi di kawasan Asia Tenggara. Sudah semenjak lama tiap etnis dan bangsa di kawasan ini mempraktikkan jenis kesenian kuna ini. Di wilayah Nusantara yang terdiri dari banyak pulau dan beraneka ragam etnis, jenis gaya wayang kulit begitu melimpah ditemui, misalnya di Pulau Jawa, wayang Narta di Bali, wayang Sasak di Lombok, wayang Banjarmasin, Palembang dan sebagainya. Kemudian di wilayah Malaya, ada wayang Siam di Kelantan, wayang Gedek di Kedah dan Perlis, wayang Melayu (Jawa) di Trengganu, Johor dan Selangor (kini sudah punah). Di Thailand ada jenis wayang Nang Yai dan Nang Thalung, belum lagi di Kamboja, Vietnam dan sebagainya.

Pengaruh Agama Hindu dan Buddha dari India sangatlah kuat di kawasan Asia Tenggara. Kebanyakan seni wayang kulit, khususnya di wilayah Nusantara, Malaya dan Thailand, mempertunjukkan kisah-kisah dari agama tersebut, seperti epik Ramayana dan Mahabharata, selain masih juga mempertunjukkan kisah-kisah asli lokal. Dengan perantaraan media wayang inilah, agama Hindu dan Buddha dapat melakukan pengajaran kepada penduduk asli di Asia Tenggara, karena media ini sendiri sudah tidak asing bagi mereka. Mungkin bisa dikatakan bahwa dalam sejarah tercatat, inilah peranan pertama wayang sebagai media diplomasi antara pertemuan budaya dan kepercayaan lokal Asia Tenggara dengan India. Dalam perjalanannya, kisah Ramayana menjadi sangat populer di Thailand dan Malaya, sementara kisah Mahabharata kurang dikenal. Wayang Siam di Kelantan banyak mempertunjukkan adaptasi Melayu dari kisah-kisah Ramayana yang disebut Hikayat Seri Rama. Justru sebaliknya di Jawa, pementasan epik Mahabharata jauh lebih dominan dilihat dari berbagai lakon carangan atau anggitan lokalnya yang begitu banyak ketimbang epik Ramayana.

Kisah-kisah India tersebut sedikit banyaknya mengalami pelokalan atau proses adaptasi dengan unsur-unsur lokal sebagai bagian dari tahapan akulturasi 
budaya. Selain masalah bahasa sastra dan musik, terjadi penambahan tokohtokoh asli lokal sebagai penyambung kisah India dengan kondisi lokal daerahnya. Misalnya pada wayang Siam di Kelantan, tampilnya Pak Dogol dan Wak Long sebagai pelayan "pribumi" dari tokoh utama Rama yang asli India. Lalu pada pewayangan Jawa ada para Panakawan dengan tokoh-tokoh seperti Ki Semar dan yang lainnya. Tokoh-tokoh asli pribumi ini selain menonjolkan kalangan rakyat jelata yang tidak terjadi pada kisah aslinya yang bernuansa feodal, diam-diam juga meninggikan peran dan keluhuran derajat pihak pribumi. Lebih jauh lagi dalam pewayangan Jawa, seting India telah berubah menjadi setting lokal, bercampur dengan mitos dan sejarah lokal. Kedua epik tersebut sudah begitu melekat dan identik dengan dunia pewayangan dan pandangan kejawaan itu sendiri.

\section{$4 \quad$ Perkembangan Wayang Kulit di Pulau Jawa}

Di Jawa, media wayang kulit ini dimanfaatkan dan dipergunakan untuk dakwah agama Islam. Ia berkembang pesat, mengalami berbagai transformasi dalam aspek visual, dan aspek pendukung lainnya seperti karawitan, sastra, dan sebagainya. Perkembangan ini melibatkan peranan dan pengaruh para ulama Sufi dan pihak penguasa lokal yang telah memeluk Islam. Bahkan Wali Sanga sendiri terlibat secara intensif di sini, terutama Susuhunan Kalijaga dan putranya Susuhunan Panggung. Mereka berusaha keras untuk mendiplomasikan antara seni wayang yang berbau non-Islam dengan ajaran Islam. Berkat peranan mereka, seni wayang kulit oleh sebagian pihak dimaknai mengandung ajaran Islam (Tarekat) dalam tiap aspeknya, meskipun masih berkisah tentang epikepik India Hindu-Buddha. Para ulama Sufi seolah memang telah siap untuk menjaga kesinambungan dengan masa lalu, dan menggunakan pemahaman (istilah) dan unsur-unsur budaya pra-Islam ke dalam konteks Islam. Nampaknya diplomasi ini memang merupakan suatu bagian dari strategi kebudayaan untuk jangka panjang ke depan.

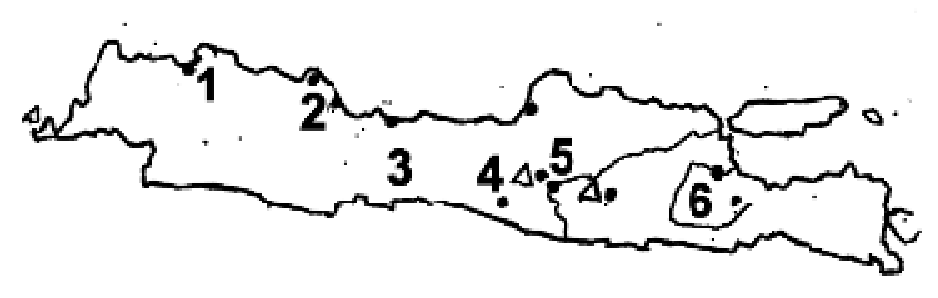

Gambar 1 Peta Pulau Jawa yang menunjukkan lokasi geografis berbagai gaya visual wayang kulit: (1) Betawi, (2) Cirebon, (3) Kedu, (4) Yogyakarta, (5) Surakarta, (6) Jawa Timuran. 
Selain para Wali, para penguasa lokal terlibat dalam usaha menggagas, merancang seni wayang ini. Misalnya Raden Patah raja Demak Bintara yang mengusulkan merombak wayang beber menjadi boneka wayang individual yang wujudnya menjauhi manusia dan bersendi lengannya, berikut penciptaan wayang Gunungan. Prakarsa ini terus dilanjutkan raja-raja Jawa berikutnyakhususnya di Jawa Tengah-seperti raja Pajang, Mataram, Kartasura, Surakarta dan Yogyakarta. Karena pengaruh sejarah bergulirnya kekuasaan raja-raja Jawa ini pulalah, lahirlah beraneka ragam corak atau gaya wayang kulit sesuai daerah-daerah di pulau Jawa yang bisa dideteksi dari masing-masing kekhasan gaya visualnya, misal Betawi, Cirebonan, Banyumasan, Yogyakarta, Surakarta dan Jawa Timuran (lihat Gambar 1).

Sebagai bukti bahwa raja-raja dan penguasa di pulau Jawa telah berlaku sebagai patron pelindung, penggemar dan pengembang seni wayang, umumnya tiap keraton di Jawa memiliki koleksi perangkat wayang kulit jimat sebagai pusaka warisan, selain pendukung lainnya seperti perangkat gamelan dan berbagai kesusastraan terkait pakem wayang yang ditulis pihak keraton. Di Surakarta dan Yogyakarta banyak kesusastraan karya pujangga keraton yang berkaitan dengan pewayangan, seperti Pustaka Raja Purwa, Serat Wedhatama, Tripama, dan sebagainya.

Bagi raja-raja Jawa, posisi seni wayang kulit sangatlah penting sebagai media diplomasi untuk berbagai kepentingan selain dakwah, di antaranya diplomasi untuk propaganda politik, pengajaran moral dan etika, pengembangan nilai dan apresiasi seni, filsafat, kebatinan, dan sebagainya.

Usaha diplomasi lainnya yaitu menbuat kisah Ramayana dan Mahabharata seolah-olah benar pernah terjadi di Pulau Jawa, dan menjadi bagian dari sejarahnya. Salah satunya dilihat dari silsilah raja-raja Jawa dalam Pustaka Raja Purwa karya Ranggawarsita yang menjadi pakem pedalangan Jawa. Hal ini masuk akal karena banyak lakonan dalam Mahabharata versi Jawa memiliki sifat pasemon yang simbolistis, yang sebenarnya merupakan sindiran halus terhadap peristiwa sejarah Jawa. Contohnya lakon Arjuna Wiwaha, Rajamala dan lain-lain. Hasilnya adalah mengakarnya kisah-kisah tersebut dengan para tokohnya di hati sanubari orang Jawa bahkan telah menjadi identitas kejawaan.

Berikutnya pada masa kolonial Belanda, budaya Barat masuk ke Nusantara dengan intensif seiring dominasi penjajahan. Namun selain beberapa ide artistik yang bersifat sebagai kosmetik dan tambahan belaka, nampaknya tak banyak pengaruh Barat yang memberikan perubahan, apalagi hingga taraf mendasar pada aspek visual wayang kulit Jawa secara umum (lihat Gambar 2). 


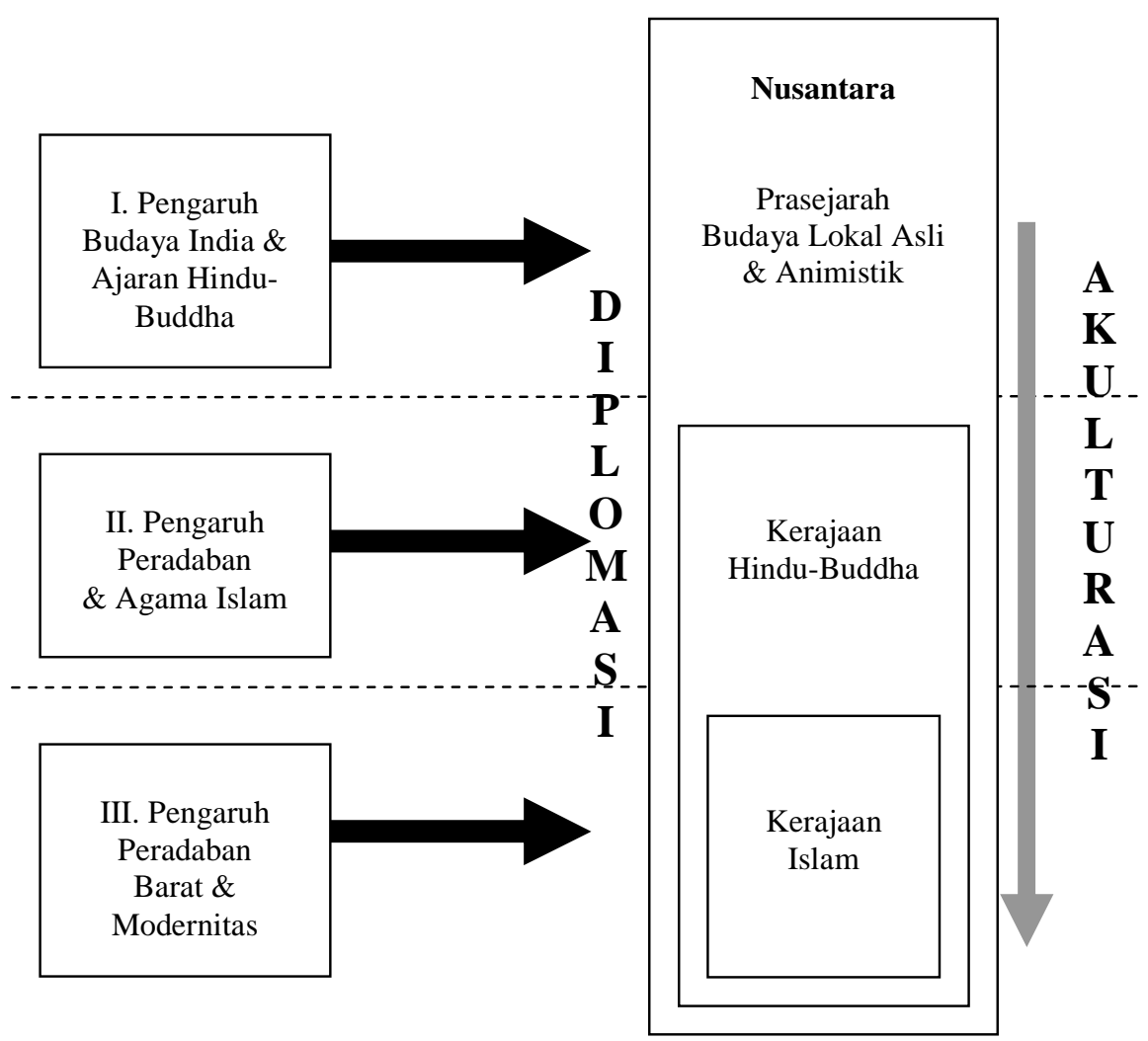

Gambar 2 Skema yang menggambarkan masuknya gelombang demi gelombang pengaruh asing ke Nusantara, berikut diplomasi dan akulturasi budaya yang terjadi.

\section{$5 \quad$ Visual Wayang Kulit Cirebon}

Dalam visual wayang kulit Cirebon nampak berbagai jejak dari beragam kepercayaan dan kebudayaan. Ragam hias megamendung-wadasan dan kehadiran wayang Buta Liyong sebagai pengaruh budaya Cina, atribut pakaian jubah dan topi pada boneka wayang Dorna sebagai pengaruh Timur Tengah. Lebih lanjut, pada gunungan Jaler Cirebon yang menampilkan wujud Dewa Ganesha sebagai pengaruh Hindu dan gunungan Istri yang dipenuhi motif wadasan. Wayang Cirebon kemudian juga menjadi media diplomasi antara budaya lokal (yang telah menyerap budaya India dan Islam) dengan budaya Barat, contohnya pada wayang Buta Topi (lihat Gambar 3 dan 4). 


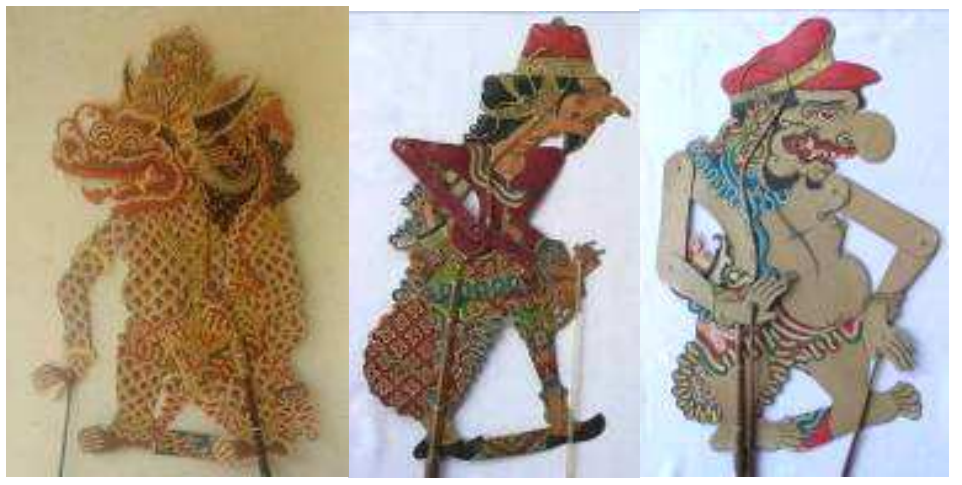

Gambar 3 Wayang Buta Liyong (Naga) koleksi Dalang Sudarga (kiri), Pandita Dorna (tengah) dan Buta Topi koleksi Dalang Mansyur, beberapa dari wayang kulit Cirebonan yang mengadopsi ide-ide artistik asing. (Foto: Haryadi Suadi).
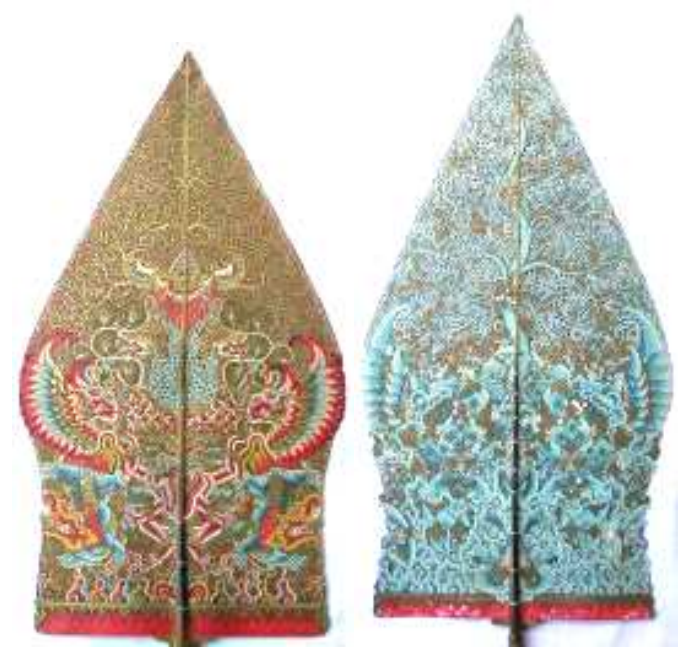

Gambar 4 Gunungan Jaler (kiri) yang menampilkan imaji Ganesha dan gunungan Istri yang dipenuhi motif wadasan, koleksi Ki Dalang Mansyur dari Gegesik, Cirebon.

Wayang kulit Cirebon merupakan contoh peralihan dari wayang zaman HinduBuddha ke wayang zaman Islam. Ini bisa dilihat karena ia masih menyisakan unsur kuna yang jelas dari imaji-imaji wayang sebelumnya seperti wayang Bali (lihat Gambar 5). Dengan mempertahankan unsur-unsur visual tertentu pada wayang Hindu tersebut, wayang kulit Cirebon menjadi media diplomasi yang 
menghubungkan leluhur dengan generasi berikutnya. Usaha tersebut bertujuan menjaga warisan kuna sekaligus mengawali sistem dan pola visual yang baru untuk wayang Jawa seterusnya (masa Islam) hingga menghasilkan wayang kulit yang lebih "modern". Sebagai contoh, wayang Surakarta sebagai puncak penyempurnaan yang unsur-unsur lamanya lebih berkurang, dialihkan atau digantikan, dan telah ditambahkan kehalusan artistik.

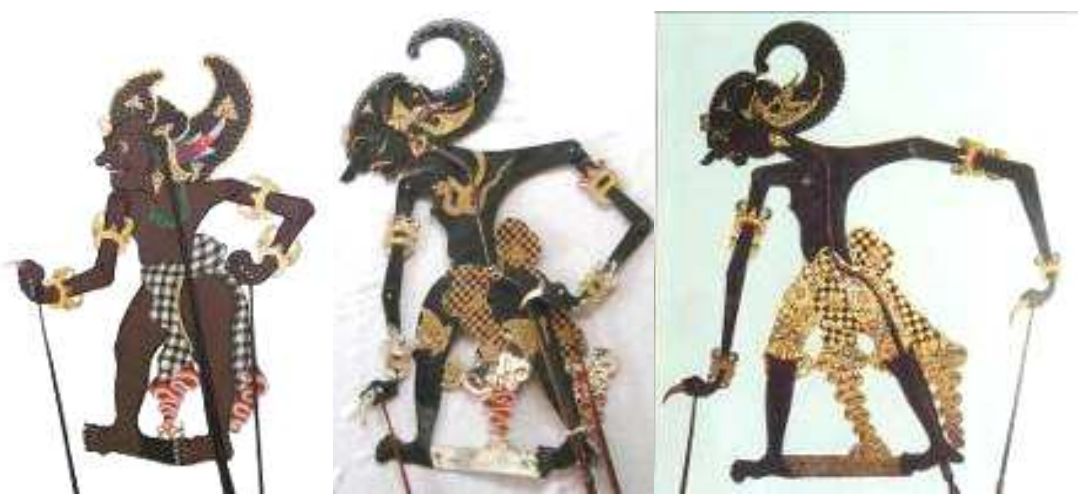

Gambar 5 Gambar wayang kulit tokoh Bima dari Bali (kiri), Cirebon (tengah) dan Surakarta (kanan). Nampak visual wayang kulit Cirebon sebagai jembatan peralihan antara wayang masa Hindu-Buddha dengan wayang masa Islam. (Repro: Guritno, Lordly Shades)

Tentunya hal ini tidak terjadi dalam waktu singkat. Hasil diplomasi itu bisa mulai terasa dalam rentang waktu yang lama, sebagai suatu proses "evolusi", mengikuti tahapan akulturasi, terlihat setelah ratusan tahun kemudian. Nampak adanya suatu strategi budaya jangka panjang yang melatarbelakangi diplomasi ini, dengan tujuan pelestarian sekaligus keterbukaan yang akan melahirkan perkembangan dan pemerkayaan.

\section{$6 \quad$ Wayang Kulit Cirebon dan Dimensi Keislaman}

Unsur-unsur dakwah Islam pada wayang kulit Cirebon masih tampak jelas, mengingat wayang masih dianggap sebagai media warisan para Wali Sanga dalam usaha dakwah dengan jalan diplomasi seni budaya. Para Wali menambahkan unsur ajaran Islam tanpa menghapuskan ajaran sebelumnya yang selain sudah terlampau mengakar pada masyarakat pribumi, juga berusaha untuk tetap melestarikan unsur-unsur postif universal di dalamnya yang dianggap tidak bertentangan dengan ajaran Islam.

Pewayangan Jawa mengalami perubahan seiring penyesuaian dengan ajaran Islam, baik dari aspek kisah, karawitan, pemaknaan tokoh dan tentunya 
visualisasi wayangnya sendiri. Visualisasi yang dulu lebih naturalis-realis, kemudian mengalami distorsi dan stilasi sehingga menjauhi bentuk manusia demi memenuhi syariat Islam. Belum lagi pemaknaannya. Hal ini terjadi karena dukungan penuh dari pihak-pihak penguasa lokal, baik pada masa kerajaan, kolonial hingga republik.

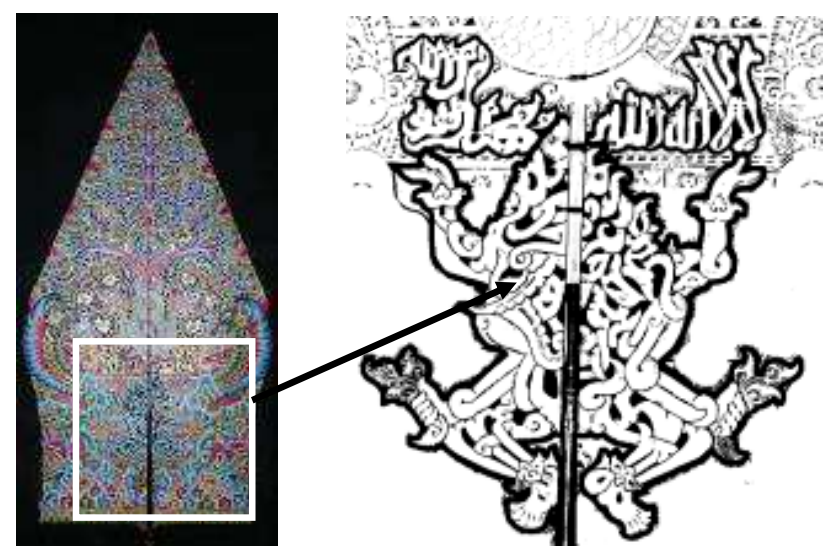

Gambar 6 Wayang Gunungan yang bertatahkan aneka kaligrafi Arab berupa tahlil, kalimat syahadat, dan shalawat, kreasi Rastika dari Gegesik, Cirebon.

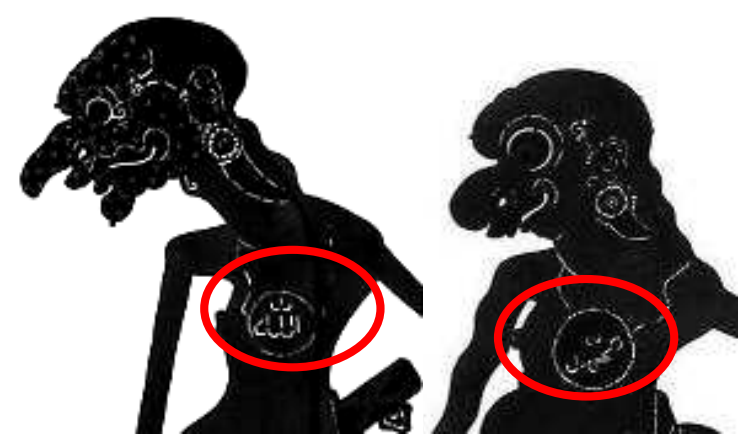

Gambar 7 Siluet wayang tokoh Panakawan Cungkring dengan kalung yang bertuliskan lafaz "Allah" dan wayang Bagalbuntung dengan kalung berlafazkan "Muhammad". Keduanya koleksi Dalang Kadrawi di Cirebon (Foto: Haryadi Suadi).

Pada wayang Cirebon, umumnya visualisasi ala wayang Hindu masih tersisa kuat. Inilah sebabnya wayang Cirebon bisa dianggap sebagai wayang kuna. Namun di lain pihak banyak wayang kulit Cirebonan kreasi baru telah menam- 
pakkan pengaruh Islam yang masif. Misalnya wayang Gunungan Jaler kreasi Rastika dari Gegesik dengan menampilkan wujud Ganesha yang tersusun atas kaligrafi Arab, berlafalkan kalimat tahlil, shalawat, dan syahadat (lihat Gambar 6). Juga sejumlah kreasi atau modifikasi wayang kulit lainnya (lihat Gambar 7). Ini menunjukkan bahwa fungsi diplomasi pada wayang Cirebon tetap berjalan.

\section{Rediplomasi Wayang terhadap Perkembangan Kontemporer}

Yang justru mengancam seni wayang di Indonesia adalah perkembangan budaya populer modern, kemajuan teknologi media dan hiburan yang memicu perubahan pola hidup dan pola pikir yang lebih praktis, pragmatis, serba cepat dan instan, pengutamaan sensasi dan aksi semata, mengurangi kadar perenungan dan spiritualitas.

Sebenarnya sejak pertengahan abad ke-20 beberapa pihak praktisi pedalangan Jawa mencoba menyiasati hal ini. Pemakaian sound sistem, lighting, pakeliran padat, boneka wayang yang dimodifikasi (termasuk pengembangan wanda baru, kreasi iseng, bisa putus, dan sebagainya), kisah-kisah carangan/anggitan dengan tema dan dialog yang lebih mengkini dan aktual hingga dimasukkannya selingan berupa musik campur sari, tarling, dangdutan, pelawak dan door prize. Termasuk perubahan konstruksi panggung seperti di Jawa Tengah (kini menjadi umum) yang menyaksikan langsung dari belakang dalang, sehingga bisa menikmati wayang secara utuh dengan warnanya, sekaligus memungkinkan interaksi langsung antara pelaku seni dan pemirsanya.

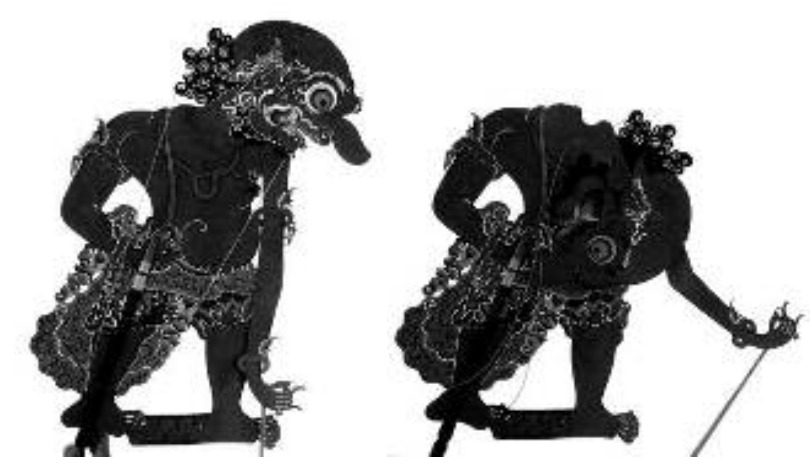

Gambar 8 Siluet boneka wayang Denawa yang telah dimodifikasi agar bisa menampilkan adegan "terpenggal", koleksi Ki Dalang Mansyur dari Gegesik, Cirebon. (Foto: Haryadi Suadi).

Usaha-usaha "kompromistis" ini bukanlah tanda dari lenyapnya tradisi atau kekalahan budaya seperti yang selama ini dikhawatirkan, namun merupakan 
suatu adanya upaya diplomasi menghadapi budaya modern populer tadi, seperti yang telah terjadi sepanjang sejarah pedalangan itu sendiri. Diplomasi yang dilandasi suatu strategi budaya jangka panjang untuk menghindari konflik terbuka, yang bisa-bisa akan merugikan posisi seni budaya itu sendiri.

Wayang Cirebon tetap menjadi duta diplomasi hingga kini, yaitu diplomasi yang mempertemukan dan menyatukan warisan leluhur, aneka budaya, kisahkisah epik India, ajaran tarekat, isu-isu kontemporer, hiburan modern, media dan teknologi dengan seni kerajinan tradisional, bahan-bahan organik (kulit dan tulang kerbau). Diplomasi yang mempertemukan berbagai kepentingan pula, yaitu kepentingan pelestarian budaya, dokumentasi sejarah, propaganda dan dominasi politik, penyebaran agama, pergaulan sosial, perkembangan kesenian dan penerapan teknologi media.

Semua pihak terkait sewajarnya memahami kelebihan seni pertunjukan yang satu ini, yaitu hakikat wayang kulit sebagai media diplomasi lintas budaya dan kepercayaan. Wayang kulit Cirebon merupakan refleksi keberhasilan diplomasi lintas budaya di masa lalu dalam skala regional, dan bisa menjadi proyeksi dari suatu alternatif keberhasilan diplomasi di masa depan dalam skala global, bahkan universal (lihat Gambar 8).

Hal ini direfleksikan juga oleh sejarah Cirebon yang pernah jaya sebagai kerajaan yang berdiri di atas pluralitas budaya, etnis, kepercayaan dengan wilayahnya yang berada di pesisir, persilangan Sunda-Jawa dan tentunya karena wataknya yang terbuka dan tanggap pada dunia luar. Sesuai dengan asal kata "caruban" yang bermakna "campuran".

\section{$8 \quad$ Kesimpulan}

Nenek moyang bangsa Asia Tenggara, dalam hal ini di Jawa, Cirebon, telah mempraktikkan konsep think globally, act locally, terbukti dari adaptasi kisahkisah India ke dalam media seni wayang kulit. Mereka sudah memahami dan menyadari prinsip primordialisme, di mana produk-produk budaya asing akan lebih bisa diakui dan dianggap sebagai milik sendiri, jika ada berbagai ikon lokal yang ditambahkan. Dalam hal ini tokoh dan konteks lokal Jawa yang ditambahkan dalam kisah Mahabharata dan Ramayana. Ini membuktikan kemampuan diplomatis seni wayang dalam menyaring dan menyerap budaya asing, sekaligus menjadikannya lokal, atau untuk sekedar memperkaya karya lokal. Demikian pula halnya dalam dimensi syiar Islam yang dilakukan para Wali, yaitu memasukkan unsur-unsur Islam pada aspek visual dan nonvisual.

Sepanjang sejarahnya perkembangan wayang di Jawa tidak terlepas dari dukungan pihak-pihak berpengaruh, baik para Wali, penguasa-penguasa lokal 
masa kerajaan, masa kolonial hingga pemerintahan zaman republik. Ini memperlihatkan bahwa para penguasa lokal pun menyadari kekuatan wayang sebagai media diplomasi untuk berbagai kepentingan. Sedangkan dari sudut pandang keislaman, media wayang kulit ini merupakan suatu contoh yang menarik, inspiratif, bahkan ideal dalam sejarah dakwah di Pulau Jawa.

\section{Referensi}

[1] Azra, A. 2006. Islam in the Indonesian World: An Account of Institutional Formation, Bandung: Mizan Pustaka.

[2] Budiono, K. 1986. Karya Skripsi. Rupa Wayang Kulit Cirebon, Studio Seni Patung, Jurusan Seni Murni, FSRD, Institut Teknologi Bandung.

[3] Cohen, M.I. 1997. An Inheritance from the Friends of God: The Southern Shadow Puppet Theatre of West Java, Indonesia, Dissertation, Faculty of the Graduate School of Yale University.

[4] Djajasoebrata, A. 1999. Shadow Theatre in Java: The Puppets, Performance \& Repertoire, Amsterdam: The Pepin Press.

[5] Guritno, H. \& Pandam. 1989. Lordly Shades: Wayang Purwa Indonesia, Jakarta: PT. Jayakarta Agung Ofset.

[6] Hardjowirogo, R. 1953. Sedjarah Wajang Purwa, Jakarta: Balai Pustaka.

[7] Holt, C. 2000. Melacak Jejak Perkembangan Seni di Indonesia. Masyarakat Seni Pertunjukan Indonesia, Bandung: Penerbit Artline.

[8] Kantor Pariwisata Seni \& Budaya. 2003. Cerita Galur Wayang Kulit Purwa Cirebon, Bagian 1-Kasultanan Kanoman, Kantor Pariwisata Seni dan Budaya, Kabupaten Cirebon.

[9] Lombard, D. 1996. Nusa Jawa: Silang Budaya-Kajian Sejarah TerpaduBagian I, II \& III, Jakarta: Penerbit PT. Gramedia Pustaka Utama.

[10] Poespaningrat, R.M.P. 2005. Nonton Wayang dari Berbagai Pakeliran, Yogyakarta: Kedaulatan Rakyat.

[11] Pramana, M.I. 2007. Karya Tesis, Tasawuf dan Perupaan pada Wayang Kulit Purwa Cirebon dan Surakarta, Program Magister Seni Rupa dan Desain, ITB

[12] Purjadi. 2007. Pengetahuan Dasar Wayang Kulit Cirebon, Badan Komunikasi Kebudayaan \& Pariwisata Kabupaten Cirebon.

[13] Sajid, R.M. 1971. Bauwarna Kawruh Wayang, Djilid 1-2, Surakarta: Penerbit Widya Duta.

[14] Simuh. 1995. Sufisme Jawa: Transformasi Tasawuf Islam ke Mistik Jawa, Yogyakarta: Yayasan Bentang Budaya.

[15] Sunardjo, U. 1983. Meninjau Sepintas Panggung Sejarah Pemerintahan Kerajaan Cerbon 1479-1809, Bandung: Tarsito.

[16] The Times Travel Library. 1990. Cirebon, Singapore: Times Editions.

[17] Karnjanatawe, K, Poetry in Motion, Bangkok Post, http://www.bangkok post.com/print/23609/poetry-in-motion (10 September 2009). 
[18] Hui, L.S., Keeper of Tradition, The Star Online, http://thestar.com.my/ lifestyle/story.asp?file=/2006/10/7/lifefocus/1564 6321\# (7 Oktober 2006).

[19] The Ramayana in Southeast Asia. Malaysia, http://orias.berkeley.edu/ SEARama/Rama Malaysia.htm.

[20] Wright, B.S. Islam and the Malay Shadow Play: Aspects of the Historical Mythology of the Wayang Siam, MelayuOnline.com. http://melayuonline.com/eng/ article/read/791 (5 September 2008). 